\title{
Investigation into the Adsorption of Methylene Blue and Methyl Orange by UiO-66- $\mathrm{NO}_{2}$ Nanoparticles
}

\author{
Hien Thi Dinh, Nam Trung Tran, and Dai Xuan Trinh \\ Faculty of Chemistry, VNU University of Science, Vietnam National University, 19 Le Thanh Tong, Hoan Kiem, Hanoi, Vietnam \\ Correspondence should be addressed to Dai Xuan Trinh; daitx@vnu.edu.vn
}

Received 11 February 2021; Revised 9 May 2021; Accepted 8 June 2021; Published 14 June 2021

Academic Editor: Dang Quoc Thuyet

Copyright (c) 2021 Hien Thi Dinh et al. This is an open access article distributed under the Creative Commons Attribution License, which permits unrestricted use, distribution, and reproduction in any medium, provided the original work is properly cited.

In this work, the adsorptive removal of methylene blue and methyl orange by UiO-66- $\mathrm{NO}_{2}$ nanoparticles was studied. The influence of $\mathrm{pH}$ on the adsorption capacity was assessed. The kinetics of the adsorption process were investigated and compared with pseudo-first-order, pseudo-second-order, Elovich, and intraparticle models. The kinetics of the adsorption fits moderately with the pseudo-first-order, but perfectly fits with pseudo-second-order models, and has a very good fit with the Elovich and intraparticle models. The adsorption isotherms were measured and compared with the Langmuir and Freundlich models. The adsorption capacity of methyl orange $(\mathrm{MO})$ on $\mathrm{UiO}-66-\mathrm{NO}_{2}$ nanoparticles $(142.9 \mathrm{mg} / \mathrm{g})$ was over three times higher than that of methylene blue (MB) on the nanoparticles $(41.7 \mathrm{mg} / \mathrm{g})$. The discrepancy between these capacities was attributed to the presence of the $-\mathrm{NO}_{2}$ functional group, which caused a strong negative mesomeric effect in the metal-organic framework structure.

\section{Introduction}

Water is unarguably an indispensable part to maintain human lives on earth. Therefore, it should be protected and used rationally. However, the water source has been potentially damaged by different activities of humans. Among these, it is agreed that the textile industry consumes a huge amount of fresh water for the production [1]. Importantly, during the production, different types of dyes are used [2]. These compounds can pollute into the water body if wastewater from the textile industry is not treated adequately [3]. The resulting pollution poses different adverse effects to the creatures living in the water body. The presence of dyes in water hinders the photosynthetic processes, thus lowering the concentration of dissolved oxygen. Low dissolved oxygen concentration can lead to different types of diseases and, in worse cases, to the death of the living creatures therein [4-6]. Moreover, many dye compounds are considered as potentially mutagenic, carcinogenic, and highly toxic [7-9]. The intake of water heavily contaminated with these dyes causes diseases in humans, for instance, allergy, central nervous system disorder, and cancer. These diseases are related to different metabolisms of dye molecules in the human body [10]. Dye molecules can substitute enzymatic cofactors in humans, thus inactivating the function of the enzymes. They can also form conjugates with human serum albumin. Additionally, they can have strong interaction with DNA, which leads to the damages and distortion of DNA [11]. These issues are worsened due to the persistence of the dyes in the environment [12]. Several dyes were found to have a half-life of up to 13 years [13]. Several others might be degraded faster, but the decomposition process gives rise to the formation of mutagenic and carcinogenic intermediate molecules [14].

Due to the persistence of the dye molecules, they are not degradable during the biological treatment of a conventional wastewater treatment plant. Therefore, special treatment methods are required for these compounds. Suitable chemical processes include ozonation, Fenton oxidation, photochemical treatment, oxidation with hyperchlorite, and electrochemical destruction [15-17]. On the contrary, physical methods to treat dyes include membrane filtration and adsorption [15-21]. Adsorption is considered as a fast method to treat dye pollution which effectively works with different types of dyes. Among different adsorbents used for this method, metal-organic framework (MOF) materials 
have attracted increasing attention due to their particularly high specific surface areas [22-24].

Metal-organic frameworks (MOFs) are porous material class composed of inorganics salts and multidentate organic linkers. Metal-organic frameworks have been widely investigated for the recent two decades because of their advantages such as superior high surface area, tunable texture, and structure diversity, which make MOF suitable for gas and liquid adsorption and separation, catalysis, drug delivery, and wastewater treatment processes. In terms of dye adsorption, MOFs have emerged as promising materials. Muhamet et al. reported that $\mathrm{Cu}-\mathrm{BTC}$ was a superior adsorbent for the removal of methylene blue with the adsorption capacity about $200 \mathrm{mg} / \mathrm{g}$ [25]. In another research, Ying et al. synthesized a 3D anionic MOF to adsorb rhodamine $\mathrm{B}$ and methylene blue, and they found that the adsorption capacity of the material reached $100 \mathrm{mg} / \mathrm{g}$ [26]. Zha et al. reported that a superhydrophobic MOF exhibited enhanced dye adsorption ability, and the adsorption capacity of the hydrophobic MOF reached $478 \mathrm{mg} / \mathrm{g}$ compared to $243 \mathrm{mg} / \mathrm{g}$ of the pristine hydrophilic MOF [27]. These results opened an emerging class of materials for dye adsorption.

Zirconium-based MOF family has been known as the most stable MOFs because of their largest coordination between the metal node and the organic linker, which prevents the metal node from the attack of chemicals. As a result, the MOFs maintain their structure in the presence of solvents such as water, ethanol, DMF, and chemicals. Among members of the family, UiO-66 has been investigated the most in adsorption applications, and most of them exhibit the outstanding performance of UiO-66. However, Chen et al. investigated the adsorption ability of UiO-66$\mathrm{NH}_{2}$ to dyes and reported that the electrostatic interaction between the functional group of the adsorbent and the adsorbate drastically governs the adsorption capacity of the materials [28]. In other words, the functional groups play a crucial role in the selective adsorption ability of MOFs. Apart from containing the functional group, $\mathrm{UiO}-66-\mathrm{NO}_{2}$ has been known as the MOF which is stable in the broadest range of $\mathrm{pH}$ [29], which endows $\mathrm{UiO}-66-\mathrm{NO}_{2}$ an ability in a broad $\mathrm{pH}$ range application.

In this research, for the first time, $\mathrm{UiO}-66-\mathrm{NO}_{2}$ was applied to remove the dyes. The characterization of UiO-66$\mathrm{NO}_{2}$ was performed using the FT-IR, XRD, TGA, and nitrogen adsorption/desorption techniques. The adsorption performance of the MOF was investigated on the removal of methylene blue (MB) as a cationic dye and methyl orange (MO) as an anionic dye whose structures are given in Figure 1. The Langmuir and Freundlich isotherms were examined, and the adsorption capacity and kinetics of the adsorption process were also performed. The research may offer a promising material for industrial applications.

\section{Experimental}

2.1. Chemicals. Zirconium tetrachloride $\left(\mathrm{ZrCl}_{4}\right.$, purity $>99.9 \%$ ) was purchased from Sigma-Aldrich. 2Nitroterephthalic acid (purity $>98.0 \%$ ) was obtained from Acros Organics. Dimethylformamide (DMF) was received from Wako Chemical Industries Ltd. Methylene blue (MB, purity $>98.0 \%$ ) and methyl orange (MO, purity $>98.0 \%$ ) were bought from TCI Chemicals Ltd. These chemicals were employed without further purification.

2.2. Characterization. Transmission FT-IR spectra were acquired in $\mathrm{KBr}$ pellets using a Jasco FTIR-6100 spectrometer. The measurement was carried out in the range of $450-1650 \mathrm{~cm}^{-1}$. X-ray diffraction (XRD) was analyzed on a Rigaku SmartLab diffractometer using $\mathrm{Cu} \mathrm{K} \alpha$ radiation with $\lambda=1.54 \AA$ at $40 \mathrm{kV}$ and $30 \mathrm{~mA}$ in the interval $2 \theta=5-40^{\circ}$. Thermal gravimetric analysis (TGA) was performed on Mettler Toledo DSC 820 under air atmosphere in the range of $30-700^{\circ} \mathrm{C}$ at a heating rate of $5^{\circ} \mathrm{C} \cdot \mathrm{min}^{-1}$. The nitrogen adsorption-desorption analysis was conducted on NOVAtouch LX4 at $77 \mathrm{~K}$. The sample was dried at $100^{\circ} \mathrm{C}$ in a vacuum oven for $3 \mathrm{~h}$ before the measurement.

\subsection{Preparation of UiO-66-NO $\mathrm{NO}_{2}$ Nanoparticles.} UiO-66- $\mathrm{NO}_{2}$ nanoparticles were prepared according to previous studies $[30,31]$. In a typical procedure, $0.28 \mathrm{~g}$ of 2 nitroterephthalic acid and $0.22 \mathrm{~g}$ of zirconium tetrachloride were dissolved in $60 \mathrm{ml}$ of DMF under nitrogen atmosphere. The solution was transferred into a Teflon-lined autoclave before being heated at $100^{\circ} \mathrm{C}$ for $24 \mathrm{~h}$. UiO-66- $\mathrm{NO}_{2}$ nanoparticles were obtained as precipitates which were washed several times with methanol before being dried at $100^{\circ} \mathrm{C}$ in a vacuum oven for $24 \mathrm{~h}$.

2.4. Adsorption Procedure. $10.0 \mathrm{ml}$ of a dye solution of a chosen concentration between 20 and $400 \mathrm{mg} \cdot \mathrm{L}^{-1}$ was subjected into an Erlenmeyer flask. To the solution, $0.01 \mathrm{~g}$ of $\mathrm{UiO}-66-\mathrm{NO}_{2}$ adsorbent was added before being well shaken. After a certain time, an aliquot was taken from the solution. The concentration of the dye in the aliquot was measured by $\mathrm{UV}-\mathrm{V}$ is spectroscopy at 665 and $465 \mathrm{~nm}$ for MB and MO, respectively. The concentration of the dye adsorbed onto UiO-66- $\mathrm{NO}_{2}$ was calculated as the following:

$$
q=\frac{C_{0}-C_{t}}{M} \cdot V
$$

where $C_{0}$ is the initial dye concentration $\left(\mathrm{mg} \cdot \mathrm{l}^{-1}\right), C_{t}$ is the dye concentration at time $t\left(\mathrm{mg} \cdot \mathrm{L}^{-1}\right), M$ is the amount of $\mathrm{UiO}-66-\mathrm{NO}_{2}(\mathrm{~g})$, and $V$ is the volume of the solution (L).

The removal percentage of the dye was calculated as the following:

$$
R=\frac{C_{0}-C_{t}}{C_{0}} \cdot 100 \%,
$$

where $C_{0}$ is the initial dye concentration $\left(\mathrm{mg} \cdot \mathrm{L}^{-1}\right)$ and $C_{t}$ is the dye concentration at time $t\left(\mathrm{mg} \cdot \mathrm{L}^{-1}\right)$.

\section{Results and Discussion}

3.1. Characterization of UiO-66-NO $\mathrm{N}_{2}$ Nanoparticles. The prepared $\mathrm{UiO}-66-\mathrm{NO}_{2}$ nanoparticles were analyzed by FTIR spectroscopy (Figure 2(a)). The spectrum displays typical 

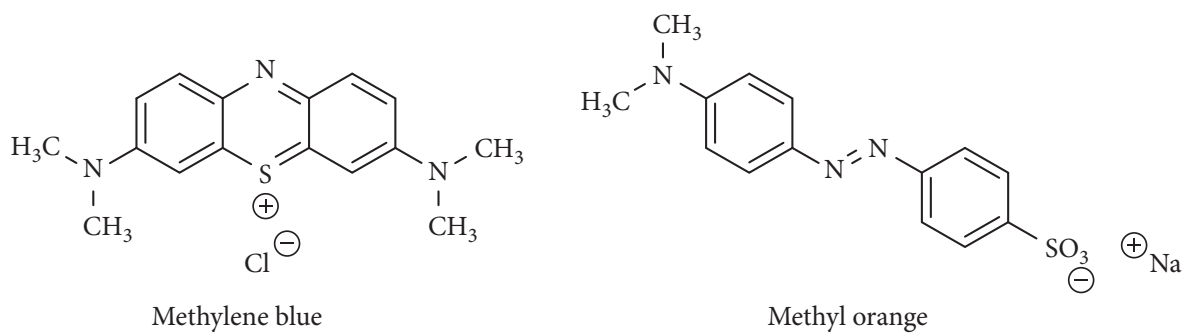

Methyl orange

Figure 1: Chemical structures of methylene blue (MB) and methyl orange (MO).

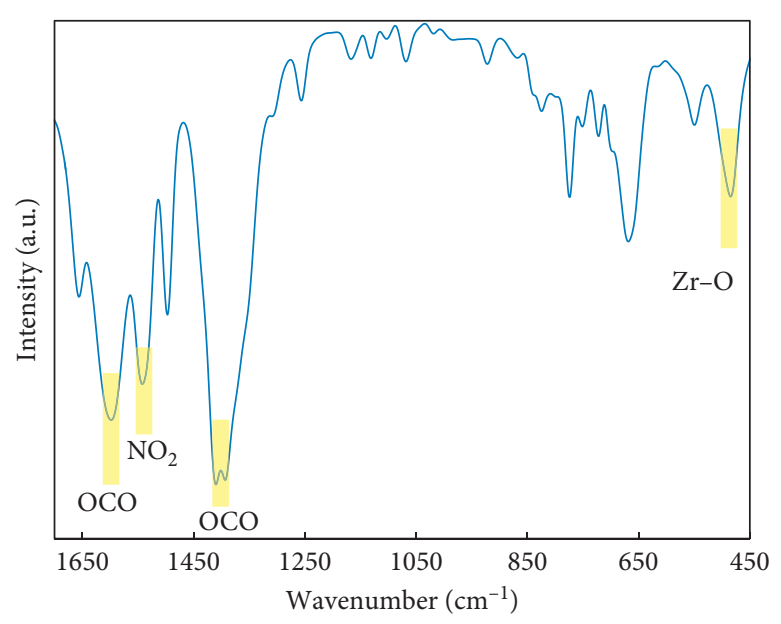

(a)

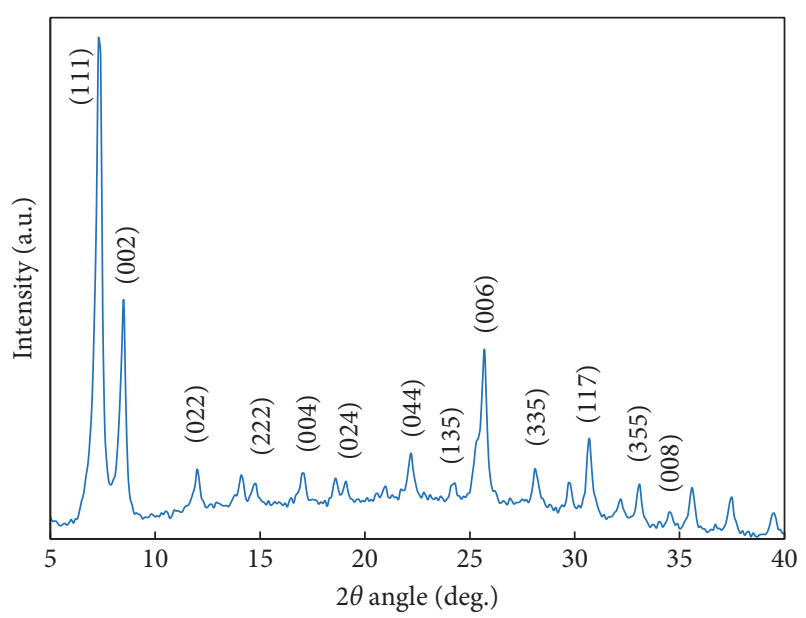

(b)

Figure 2: FTIR spectra (a) and XRD diffractogram (b) of prepared UiO-66- $\mathrm{NO}_{2}$ nanoparticles.

bands responsible for the functional groups $\mathrm{C}=\mathrm{O}(1597$ and $\left.1400 \mathrm{~cm}^{-1}\right), \mathrm{NO}_{2}\left(1544 \mathrm{~cm}^{-1}\right)$, and $\mathrm{Zr}-\mathrm{O}\left(484 \mathrm{~cm}^{-1}\right)$. Compared to the bands of UiO-66 materials [32], those of UiO66- $\mathrm{NO}_{2}$ material were slightly shifted to the lower wavelength. The reason for this shift is probably due to the negative mesomeric effect resulted by the $-\mathrm{NO}_{2}$ groups in the structure of $\mathrm{UiO}-66-\mathrm{NO}_{2}$ material, which weakens the corresponding $\mathrm{C}=\mathrm{O}$ and $\mathrm{C}=\mathrm{C}$ bonds.

On the contrary, the XRD diffractogram of UiO-66- $\mathrm{NO}_{2}$ material shows the typical peak of the face-centred cubic structure of the UiO-66 ( $\mathrm{Zr}$ )-based metal-organic framework family [31, 33-35] such as peaks at 7.3, 8.4, and $11.9^{\circ}$ corresponding to the (111), (002), and (022) planes, respectively (Figure 2(b)). In addition, the TEM image of UiO66- $\mathrm{NO}_{2}$ material shows particles with size in the range 45-65 nm (Figure S1, Supplementary Materials). The small size of the material allows maximal contact with the adsorbents, which is beneficial for the adsorption process. The nitrogen sorption isotherm of $\mathrm{UiO}-66-\mathrm{NO}_{2}$ material is displayed in Figure 3(a). It represents an isotherm categorised as type I, which is a characteristic for microporous materials. The BET specific surface area is $970.2 \mathrm{~m}^{2} \cdot \mathrm{g}^{-1}$, which is higher than the value of the UiO-66- $\mathrm{NO}_{2}$ material in the study carried out by Rada et al. $\left(771.0 \mathrm{~m}^{2} \cdot \mathrm{g}^{-1}\right)$ [36]. However, it is lower than the value of $\mathrm{UiO}-66-\mathrm{NH}_{2}$ in the same study $\left(1025 \mathrm{~m}^{2} \cdot \mathrm{g}^{-1}\right)$. In the study of Song et al. [37], the BET surface of UiO-66 was found up to $1684 \mathrm{~m}^{2} \cdot \mathrm{g}^{-1}$. Noticeably, this value decreases with an increasing amount of water and solvent contents, which remain in the pores of the material. The positions filled with water and solvent molecules are considered as defects of the material structure $[38,39]$.

The TGA diagram of UiO-66- $\mathrm{NO}_{2}$ is displayed in Figure 3(b). As can be seen, from 40 to $174^{\circ} \mathrm{C}$, a loss of $18.2 \mathrm{wt} \%$ was observed, which is responsible for the removal of water and ethanol from the material. The subsequent loss is assigned to the deviation of DMF molecules adsorbed on the surface of the material. After this loss, another weight loss of $57.7 \%$ was observed from 190 to $512^{\circ} \mathrm{C}$, which is corresponding to the rupture of the benzene and carbonyl groups. After $512^{\circ} \mathrm{C}$, the material shows a residue of $24.0 \%$ which is assigned to the remaining $\mathrm{ZrO}_{2}$.

\subsection{Adsorption of Methylene Blue and Methyl Orange onto UiO-66- $\mathrm{NO}_{2}$ Nanoparticles}

3.2.1. Adsorption Kinetics. In principle, the adsorption of dyes can be divided into at least four major stages. The first stage involves the mass transfer of dye molecules towards the adsorbents (bulk movement). Unless stirring is set at particularly low speeds, this stage is a fast process which takes place right after the addition of the adsorbents into the aqueous solution. When the dye molecules are about the adsorbents, the second stage is initiated, which involves a slow diffusion of these molecules towards the surface of the 


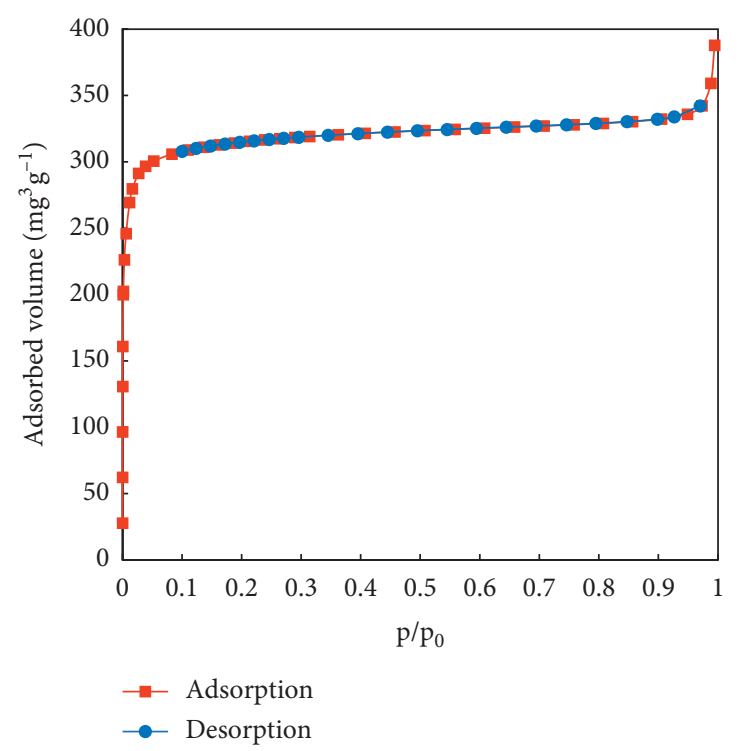

(a)

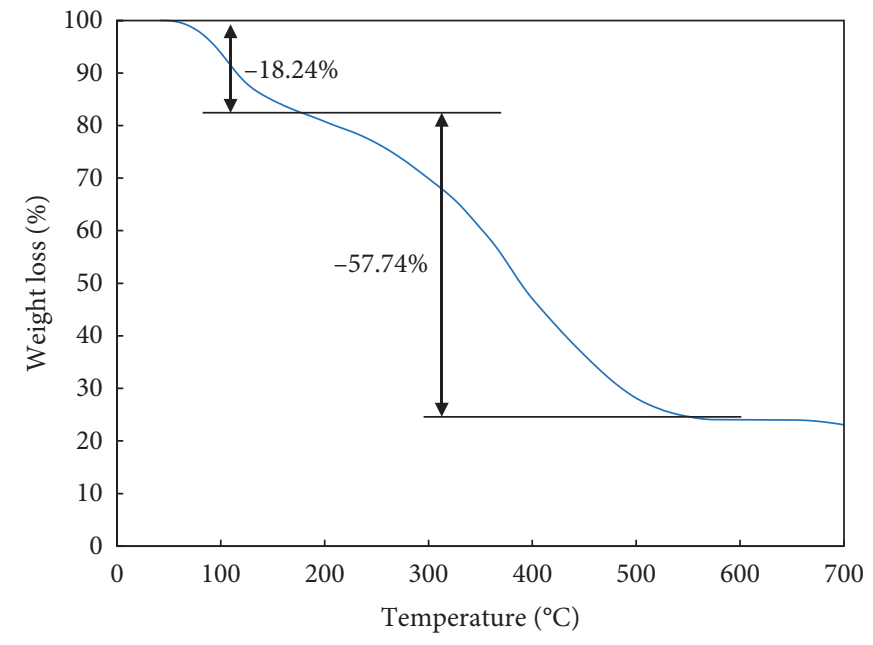

(b)

FIGURE 3: TGA diagram and nitrogen adsorption isotherm of the prepared UiO-66- $\mathrm{NO}_{2}$ material.

adsorbents (film diffusion). It is followed by the third stage, which is a slow diffusion of the dye molecules into the pores of the adsorbents (intraparticle diffusion). During the final stage, the dye molecules are rapidly anchored to the active sites of the adsorbents. Generally, the film and the intraparticle diffusions qualitatively determine the rate of the adsorption of the dyes onto the adsorbents. Among them, one factor might be more predominating than the other in certain cases. At low dye concentration, the film diffusion is more predominating, while the intraparticle diffusion has a greater impact on the rate of the adsorption in many other cases.

The adsorption of $\mathrm{MB}$ and $\mathrm{MO}$ onto $\mathrm{UiO}-66-\mathrm{NO}_{2}$ is demonstrated in Figure 4. As can be seen, the fast bulk movement was observed in the time from 0 to $5 \mathrm{~min}$, when the concentration of $\mathrm{MB}$ and $\mathrm{MO}$ was drastically reduced from 50.0 to 22.3 and $15.9 \mathrm{mg} / \mathrm{L}$, respectively. From 5 to $35 \mathrm{~min}$, the concentration of $\mathrm{MB}$ and $\mathrm{MO}$ was reduced gradually, being controlled by the film and intraparticle diffusions.

To quantitatively describe the kinetics of the adsorption of $\mathrm{MB}$ and $\mathrm{MO}$, four popular approaches were applied, namely, (a) pseudo-first-order (PFO), (b) pseudo-secondorder (PSO), (c) Elovich, and (d) intraparticle diffusion models. Each of these models makes individual assumption about the nature of the adsorption process to enable a quantitative calculation of the kinetics. The corresponding mathematical equation was transformed into linear forms, for which regressions with the experimental data were calculated. Finally, the correlation coefficient $R^{2}$ was used to evaluate the correlation of the experiment data with the kinetics model.

In the PFO model, the kinetics of the adsorption is assumed to be proportional to the number of active sites of the adsorbent and reciprocal to the concentration of the

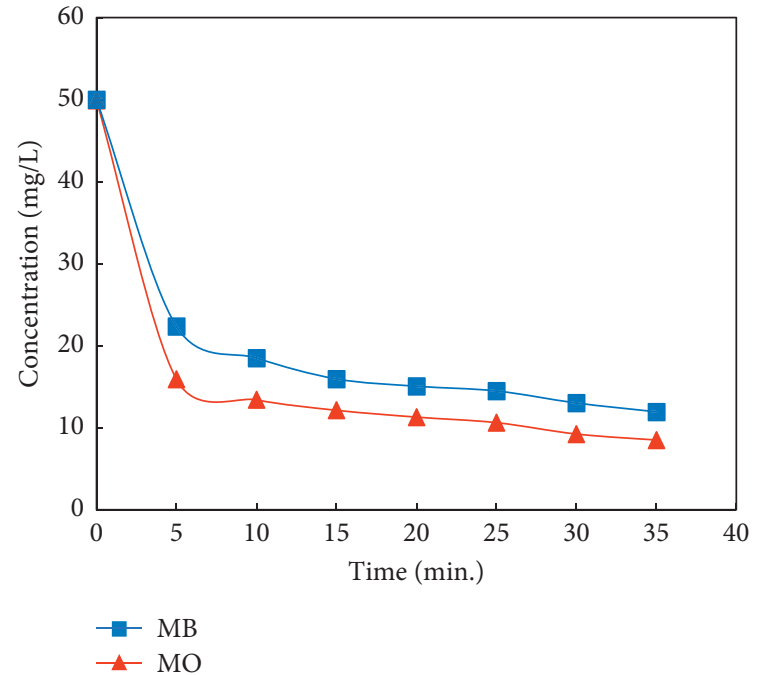

Figure 4: Adsorption of methylene blue (MB) and methyl orange (MO) by the prepared $\mathrm{UiO}-66-\mathrm{NO}_{2}$ material.

dyes. The corresponding kinetic equation is given as the following:

$$
\log \left(q_{e}-q_{t}\right)=\log q_{e}-\frac{k_{1}}{2.303} t
$$

where $q_{t}$ represents the amount of dyes adsorbed onto the adsorbent $\left(\mathrm{mg} \cdot \mathrm{g}^{-1}\right), q_{e}$ is the equilibrium adsorption capacity $\left(\mathrm{mg} \cdot \mathrm{g}^{-1}\right)$, and $k_{1}$ is the rate constant $\left(\mathrm{min}^{-1}\right)$.

Applying the experimental data into equation (3), the relationship between these parameters for $\mathrm{MB}$ is given in Figure S2. As can be seen, at the concentration of 50 and $75 \mathrm{mg} / \mathrm{L}$, there were linear relations following pseudo-firstorder reaction kinetics. However, at the concentration of $100 \mathrm{mg} / \mathrm{L}$, the correlation coefficient was only 0.83 which 
suggests that the pseudo-first-order reaction kinetics was irrelevant to adsorption of $\mathrm{MB}$ onto $\mathrm{UiO}-66-\mathrm{NO}_{2}$. It is notable to mention that, in this case, from 5 to $20 \mathrm{~min}$, a perfect linearization was observed $\left(R^{2}=0.99\right)$, which was assumed that the process from 5 to $20 \mathrm{~min}$ follows the pseudo-first-order reaction kinetics. Nevertheless, the linearization was deviated from 25 min driving the overall correlation coefficient as low as 0.83 . Therefore, the pseudo-first-order reaction kinetics may be applicable to the adsorption at a low MB uptake, and at high MB amount adsorption, the pseudo-first-order kinetics was inappropriate.

Applying the experiment data into equation (3) for $\mathrm{MO}$, the relationship between the parameters of the PFO model is derived, being given in Figure S3. There was a good fit of the $\mathrm{MO}$ adsorption to the pseudo-first-order reaction kinetics in which the correlations for 50,75 , and $100 \mathrm{mg} / \mathrm{L}$ were 0.95 , 0.95 , and 0.98 . From the linear regression, we conclude that the PFO model gives a quite representation of the experimental data for MO adsorption.

In comparison to PFO, the PSO model assumes that the rate of the adsorption process is proportional to the available active sites of the adsorbent which follows the equation

$$
\frac{\mathrm{d} q_{t}}{\mathrm{~d}_{t}}=k_{2} \cdot\left(q_{e}-q_{t}\right)^{2} \text {. }
$$

By taking the corresponding integral, the linear form of the equation is derived as the following:

$$
\frac{t}{q}=\frac{1}{k_{2} q_{e}^{2}}+\frac{t}{q_{e}} .
$$

Applying the experiment data into the linear form of equation (5), we obtained a very good correlation $\left(R^{2}=0.99\right)$ for the entire adsorption of MB and MO (Figures S4 and S5). These data suggested that the chemisorption was more preferential than physisorption for the adsorption of both dyes onto the UiO-66- $\mathrm{NO}_{2}$ nanoparticles [40]. $k_{2}$ was the rate of adsorption of the dyes which revealed that the adsorption of $\mathrm{MB}\left(k_{2}=0.064 \mathrm{~g} / \mathrm{mg} \cdot \mathrm{min}\right)$ was faster than that of MO $(0.034 \mathrm{~g} / \mathrm{mg} \cdot \mathrm{min})$ on the nanoparticles.

The Elovich model assumes that the rate of the adsorption decreases in an exponential manner with an increase in the number of dye molecules, following a chemisorption mechanism [41]. The kinetics for this model is described as the following:

$$
\frac{\mathrm{d} q_{t}}{\mathrm{~d} t}=\alpha \cdot e^{-\beta q_{t}}
$$

After taking the integral and approximation conditions, $q_{t} \approx 0, d q_{t} / d t \approx \alpha$, and $t \gg 1 / \alpha \cdot \beta$, and the corresponding linear form of equation (7) is derived:

$$
q_{t}=\frac{1}{\beta} \cdot \ln (\alpha \beta)+\frac{1}{\beta} \cdot \ln t .
$$

Applying the experiment data of MB into the linear form of equation (7), the relationship between the reaction parameters is demonstrated in Figures S6 and S7. As can be seen, the Elovich model gives a very good fit with the experimental data of MO in which $R^{2}$ was varied in the range of 0.92 to 0.99 . On the contrary, the Elovich model gives a moderate fit with the experimental data of $\mathrm{MB}$ with $R^{2}$ ranging from 0.85 to 0.97 . The good fit of the experimental data of $\mathrm{MO}$ with Elovich indicates the existence of the chemisorption interaction between this dye and the adsorbent.

In the intraparticle diffusion model, the effect of the boundary layer is considered. The application of this model might give hints whether the intraparticle diffusion is the predominant rate-determining factor. The equation of the intraparticle diffusion model is given as the following [42]:

$$
q_{t}=k \cdot t^{1 / 2}+C \text {. }
$$

Therefore, we applied the experimental data to examine the linear relationship between the variable $q_{\mathrm{t}}$ and $t^{1 / 2}$ in equation (8). The results are demonstrated in Figures S8 and S9. As can be seen, the intraparticle model gives a very good fit for MB ( $R^{2}$ from 0.91 to 0.98$)$ and excellent fit for MO $\left(R^{2}\right.$ within $0.92-0.97)$. It indicates that, in both cases, the intraparticle diffusion is the rate-determining stage of the adsorption.

3.2.2. Adsorption Isotherm. The adsorption isotherms exhibited the $\mathrm{MO}$ and $\mathrm{MB}$ adsorption onto $\mathrm{UiO}-66-\mathrm{NO}_{2}$ which are represented by the Langmuir isotherms as the following equation [43] and displayed in Figure 5.

$$
q_{e}=\frac{q_{\max } K_{L} C_{e}}{1+K_{L} C_{e}}
$$

where $q_{e}$ represents the equilibrium dye concentration in the absorbents (mg. $\left.\mathrm{g}^{-1}\right), C_{e}$ is the equilibrium dye concentration in the solution $\left(\mathrm{mg} \cdot \mathrm{l}^{-1}\right), q_{\max }$ is the monolayer adsorption capacity of the adsorbents $\left(\mathrm{mg} \cdot \mathrm{g}^{-1}\right)$, and $K_{L}$ is the Langmuir adsorption constant $\left(1 \cdot \mathrm{mg}^{-1}\right)$.

As seen in Figure 5, at the low adsorbate concentration, when the active sites for the adsorption were abundant on the adsorbent surface, the amount of MO adsorbed on the adsorbent sharply increased till the active adsorption sites on the adsorbent decrease before reaching the saturation state. The curve for $\mathrm{MB}$ adsorption was in the same scenario. However, the slope for adsorption increment at the low concentration step was significantly lower than that of $\mathrm{MO}$ adsorption. Also, the maximum adsorption of $\mathrm{UiO}-66-\mathrm{NO}_{2}$ for $\mathrm{MB}$ was far less than for MO dye. From the adsorption isotherms, the maximum adsorption capacity of $\mathrm{MO}$ on $\mathrm{UiO}-66-\mathrm{NO}_{2}$ was about $115 \mathrm{mg} / \mathrm{g}$, while the maximum value for $\mathrm{MB}$ was about $36 \mathrm{mg} / \mathrm{g}$. These data revealed that the adsorption of $\mathrm{MO}$ on the material was more favourable than that of MB.

To gain a more insightful view about the mechanism of the adsorption, we analyzed their isotherms by applying linear Langmuir and Freundlich models which are depicted in Figure 6.

The Langmuir model assumes that the adsorption of solutes onto adsorbents proceeds via the formation of a single homogenous layer of dye molecules on the surface of 


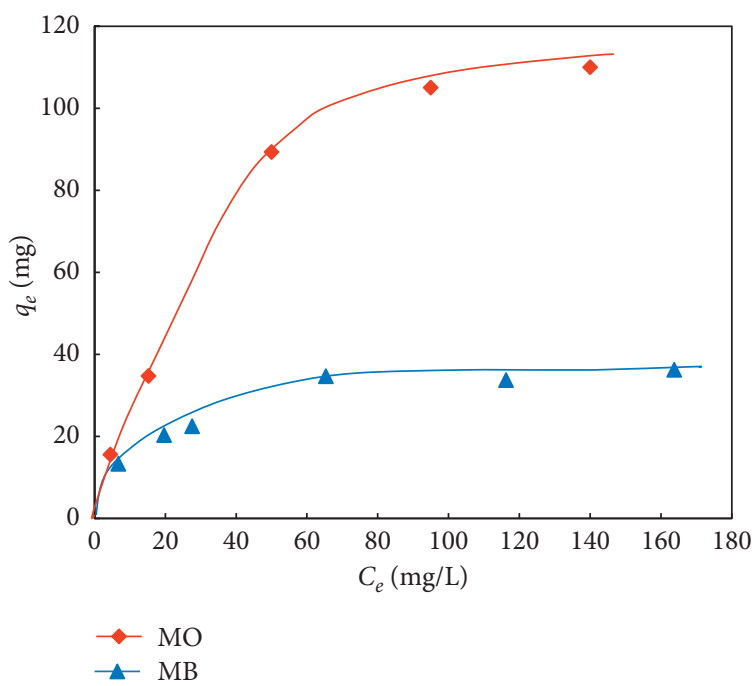

FIgURE 5: Langmuir adsorption isotherms of $\mathrm{MO}$ and $\mathrm{MB}$ adsorption onto $\mathrm{UiO}-66-\mathrm{NO}_{2}$.

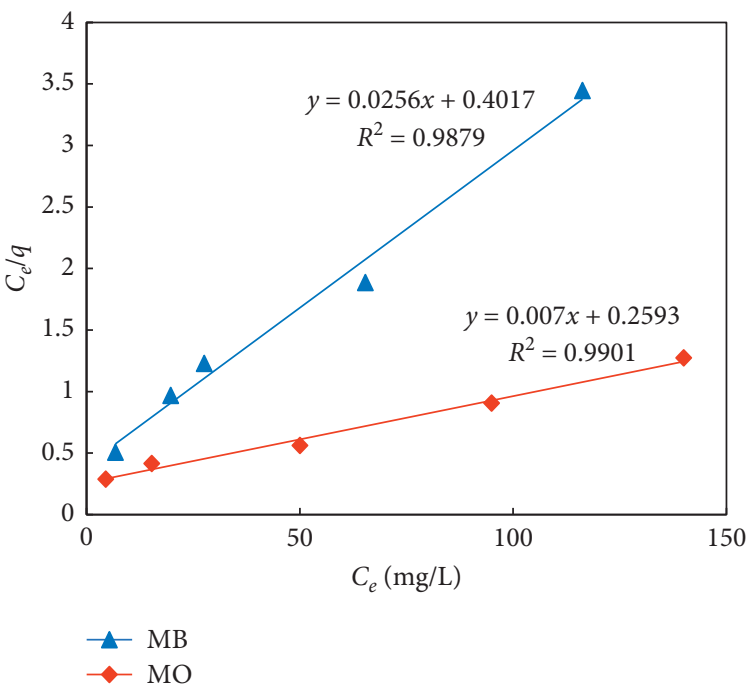

(a)

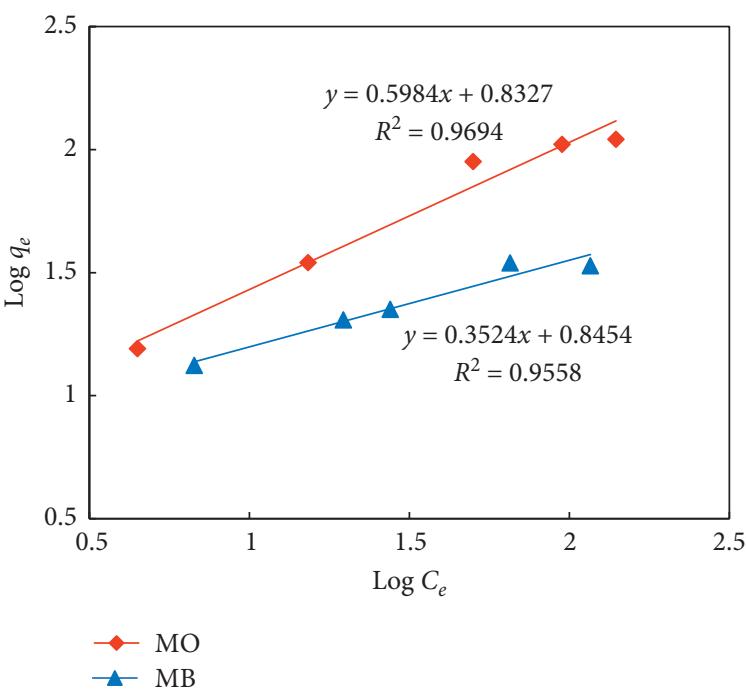

(b)

FIgURE 6: Linear isotherm models for the adsorption of MB and MO onto UiO-66- $\mathrm{NO}_{2}$.

the adsorbent. The corresponding equation for the Langmuir isotherm is given as the following [44]:

$$
\frac{C_{e}}{q_{e}}=\frac{1}{q_{\max } K_{L}}+\frac{C_{e}}{q_{\max }} .
$$

Based on this equation, the linear regression between $C_{e} / q_{e}$ and $C_{e}$ was analyzed, and the correlation coefficient $R^{2}$ and the variable $1 / q_{\max }$ were estimated. The $R^{2}$ values for $\mathrm{MB}$ and $\mathrm{MO}$ were 0.99 in both cases, indicating that the Langmuir model can be used to precisely describe the kinetics of the adsorption of $\mathrm{MB}$ and $\mathrm{MO}$ onto $\mathrm{UiO}-66-\mathrm{NO}_{2}$. The maximum monolayer adsorption $\left(q_{\max }\right)$, which represents the adsorption capacity of the adsorbent, was calculated as 41.7 and $142.9 \mathrm{mg} \cdot \mathrm{g}^{-1}$ for $\mathrm{MB}$ and MO, respectively. Interestingly, the maximum adsorption capacities of dyes on the materials estimated from linear and nonlinear models were inconsistent. The reason for the deviation was explained by the propagated error caused by the least square regression during linearization $[43,45]$.

The adsorption of dye on the metal-organic framework was reported to depend on the pore sizes of the adsorbents in some previous studies. In the study of $\mathrm{Wu}$ et al., the adsorption capacity of MO in ZIF-8 was particularly low despite its high BET specific surface area [46]. It is due to the particularly small pore size of the adsorbent that does not allow the penetration of the MO molecules into the inner pores. For this reason, the adsorption can only take place outside of the pores, for example, in the interspaces between the particles. The comparison of the adsorption capacity of this study with the results of previous studies indicates that the adsorption of $\mathrm{MB}$ and $\mathrm{MO}$ takes place in both intraparticle and interparticle spaces of $\mathrm{UiO}-66-\mathrm{NO}_{2}$. 
Furthermore, the $R_{L}$ value for $\mathrm{MB}$ and MO is estimated as 0.05 and 0.047 , respectively, indicating that the process is favourable in both cases. The $R_{L}$ value for $\mathrm{MO}$ is slightly lower than that of $\mathrm{MB}$, suggesting that the adsorption of $\mathrm{MO}$ is more favourable than MB. It is different from the results of several previous studies, in which the adsorption capacity of $\mathrm{MB}$ is higher than that of MO. The difference is probably related to the presence of the $-\mathrm{NO}_{2}$ group with a strong negative mesomeric effect in the structure of $\mathrm{UiO}-66-\mathrm{NO}_{2}$.

In comparison to Langmuir, the Freundlich model considers the heterogeneity of the surface of the adsorbents such as the repulsion between the adsorbed dye molecules. The Freundlich model is an empirical approach which follows the equation

$$
\log q_{e}=\log K_{F}+\frac{1}{n} \cdot \log C_{e}
$$

where $q_{e}$ is equal to the equilibrium concentration of dyes in the absorbents $\left(\mathrm{mg} \cdot \mathrm{g}^{-1}\right), C_{e}$ is the equilibrium concentration of dyes in the solution (mg. $\left.\mathrm{l}^{-1}\right)$, and $K_{F}\left(\mathrm{l} \cdot \mathrm{g}^{-1}\right)$ and $n$ are the Freundlich adsorption isotherm constants. Based on this equation, the linear regression between $\log q_{e}$ and $\log C_{e}$ was analyzed. The $R^{2}$ values for MB and MO were estimated as 0.95 and 0.96 , respectively. They indicate that the Freundlich model can also be used to precisely describe the adsorption of $\mathrm{MB}$ and $\mathrm{MO}$ onto $\mathrm{UiO}-66-\mathrm{NO}_{2}$. The $1 / n$ value for $\mathrm{MB}$ and $\mathrm{MO}$ is 0.31 and 0.60 , respectively. This value for $\mathrm{MB}$ is lower than $\mathrm{MO}$, indicating that the adsorption of $\mathrm{MB}$ is more heterogeneous than MO. This might be attributed to the difference in the adsorption mechanisms of these dyes.

In comparison with adsorption capacities of other MOFs in the zirconium-based family, according to Chen et al., the adsorption capacities of $\mathrm{MB}$ on $\mathrm{UiO}-66$ and $\mathrm{UiO}-66-\mathrm{NH}_{2}$ were 90.88 and $96.45 \mathrm{mg} / \mathrm{g}$, respectively, while for $\mathrm{MO}$, the adsorption capacities on $\mathrm{UiO}-66$ and $\mathrm{UiO}-66-\mathrm{NH}_{2}$ were 39.42 and $28.97 \mathrm{mg} / \mathrm{g}$. However, the adsorption capacity of $\mathrm{MO}$ on UiO-66- $\mathrm{NO}_{2}$ was outperformed than that of $\mathrm{MB}$ (Table 1). Therefore, the behavior of UiO-66 and UiO-66$\mathrm{NH}_{2}$ with cationic dye and anionic dye was reversed to that of UiO-66- $\mathrm{NO}_{2}$. This inversion in the adsorption ability of the MOFs for the dyes might result from the effect of functional groups $\left(-\mathrm{NH}_{2}\right.$ and $\left.-\mathrm{NO}_{2}\right)$ on the electrostatic nature of the frameworks, which in turn governed the electrostatic attraction/repulsion of the frameworks with the dyes.

3.2.3. Influencing Factors on the Adsorption of $M B$ and $M O$ onto Adsorbents. At first, the influence of $\mathrm{pH}$ on the adsorption of $\mathrm{MB}$ and $\mathrm{MO}$ was studied. $\mathrm{pH}$ of the solution can determine the nature of the surface of the adsorbents. The $\mathrm{pH}$ point of zero charge $\left(\mathrm{pH}_{\mathrm{pzc}}\right)$ was estimated by finding the $\mathrm{pH}$ value, in which $\mathrm{pH}_{\text {initial }}$ is equal to $\mathrm{pH}_{\text {final }}$ (Figure 7). Below $\mathrm{pH}_{\mathrm{pzc}}$, the surface of the adsorbents is protonated, thus being positively charged. Positively charged surface facilitates the anchor of anion dyes. In contrast, above the $\mathrm{pH}_{\mathrm{pzc}}$ value, the surface of the adsorbents is anchored to hydroxide ions, thus being negatively charged. Negatively charged surface facilitates the anchor of cation dyes. In this
TABLE 1: Adsorption capacities of zirconium-based MOFs for MB and MO.

\begin{tabular}{lccc}
\hline Absorbents & Dyes & $Q_{\max }(\mathrm{mg} / \mathrm{g})$ & Reference \\
\hline UiO-66 & & 39.42 & {$[28]$} \\
UiO-66- $\mathrm{NH}_{2}$ & $\mathrm{MO}(\mathrm{mg} / \mathrm{g})$ & 28.97 & {$[28]$} \\
$\mathrm{UiO}-66-\mathrm{NO}_{2}$ & & 142.9 & This work \\
\hline UiO-66 & & 90.88 & {$[28]$} \\
$\mathrm{UiO}-66-\mathrm{NH}_{2}$ & $\mathrm{MB}(\mathrm{mg} / \mathrm{g})$ & 96.45 & {$[28]$} \\
UiO-66- $\mathrm{NO}_{2}$ & & 41.7 & This work \\
\hline
\end{tabular}

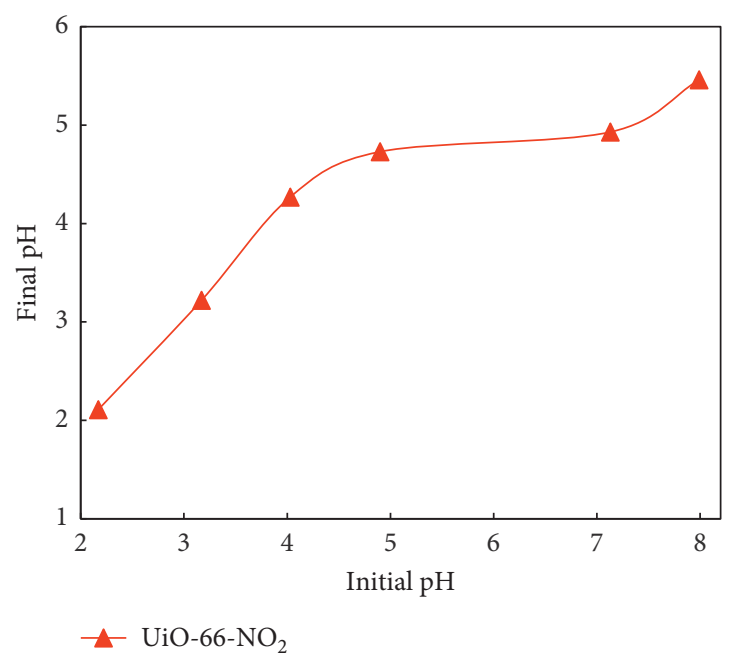

FIgURE 7: Determination of the point of zero charge $\left(\mathrm{pH}_{\mathrm{pzc}}\right)$ of $\mathrm{UiO}-66-\mathrm{NO}_{2}$.

study, the $\mathrm{pH}_{\mathrm{pzc}}$ value of the adsorbent was about 4.6 (Figure 7).

Generally, the interactions between $\mathrm{UiO}-66-\mathrm{NO}_{2}$ and dye molecules can be based on hydrogen bonds, electrostatic attraction, electrostatic repulsion, van der Waals forces, $\pi-\pi$ stacking, and acid-base interaction. The influence of $\mathrm{pH}$ on the adsorption capacity of $\mathrm{MB}$ and $\mathrm{MO}$ onto $\mathrm{UiO}-66-\mathrm{NO}_{2}$ is demonstrated in Figure 8.

The adsorption capacity of $\mathrm{MO}$ onto $\mathrm{UiO}-66-\mathrm{NO}_{2}$ is given in red color. As can be seen, from $\mathrm{pH} 2.0$ to 4.0 , the adsorption capacity of MO decreases from $37.0 \%$ to $26.0 \%$. In acidic conditions, the surface of $\mathrm{UiO}-66-\mathrm{NO}_{2}$ is positively charged where the carbonyl groups of $\mathrm{UiO}-66-\mathrm{NO}_{2}$ are protonated. The protonation hydrogen atoms can initiate further hydrogen bonds with the MO molecules. The hydrogen bonds and the electrostatic interaction enhance the attraction between $\mathrm{UiO}-66-\mathrm{NO}_{2}$ and $\mathrm{MO}$ molecules. The increase of $\mathrm{pH}$ from 2.0 to 4.0 reduces the number of positive charges and the protonation hydrogen atoms, which reduces the adsorption capacity of $\mathrm{MO}$ onto $\mathrm{UiO}-66-\mathrm{NO}_{2}$. The $\mathrm{pK}_{\mathrm{a}}$ constant for $\mathrm{MO}$ is about 3.7 [47]. It means that, at $\mathrm{pH}$ above 3.7, the majority of the MO molecules exist in the negatively charged form. From pH 4.0 to 6.0, the surface of UiO-66$\mathrm{NO}_{2}$ is quite neutral (Figure 7). Therefore, in this $\mathrm{pH}$ range, the interaction between $\mathrm{UiO}-66-\mathrm{NO}_{2}$ and $\mathrm{MO}$ molecules is majorly based on the nonelectrostatic interaction, such as $\pi-\pi$ stacking and van der Waals forces. From $\mathrm{pH} 6.0$ to 9.0, 


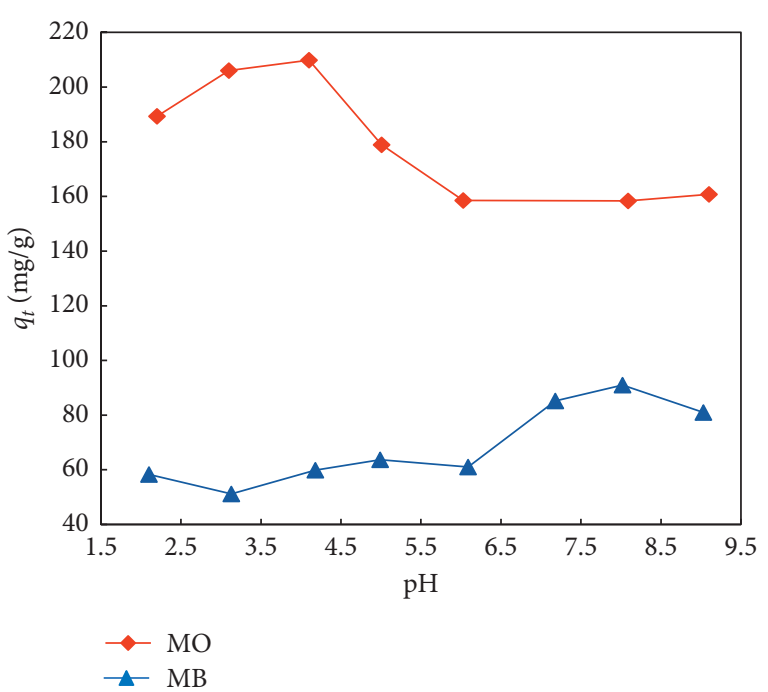

FIGURE 8: Influence of $\mathrm{pH}$ on the adsorption capacity of $\mathrm{MB}$ and $\mathrm{MO}$ by $\mathrm{UiO}-66-\mathrm{NO}_{2}$.

the adsorption capacity of $\mathrm{MO}$ onto $\mathrm{UiO}-66-\mathrm{NO}_{2}$ almost remains, indicating that the electrostatic repulsion between the negatively charged surface of $\mathrm{UiO}-66-\mathrm{NO}_{2}$ and $\mathrm{MO}$ molecules is negligible. It further indicates that the hydrogen bond interaction was predominant over electrostatic attraction in the $\mathrm{pH}$ range of 2.0 to 4.0. Overall, the adsorption between $\mathrm{UiO}-66-\mathrm{NO}_{2}$ and $\mathrm{MO}$ was majorly based on the nonelectrostatic interactions such as $\pi-\pi$ stacking and van der Waals forces. The adsorption can be enhanced owing to the formation of hydrogen bond interactions, which is clearly observed in acidic conditions and partly observed in basic conditions.

The adsorption capacity of $\mathrm{MB}$ onto $\mathrm{UiO}-66-\mathrm{NO}_{2}$ is given in blue color. The $\mathrm{pK}_{\mathrm{a}}$ constant of $\mathrm{MB}$ is 3.8 [48]. At $\mathrm{pH}$ lower than this value, the molecules exist majorly in the positively charged form. On the contrary, at $\mathrm{pH}$ above this value, the molecules exist majorly in the neutral form. From $\mathrm{pH} 2.0$ to 3.0, the adsorption capacity of $\mathrm{MB}$ is decreased. In this range, both $\mathrm{UiO}-66-\mathrm{NO}_{2}$ and $\mathrm{MB}$ molecules exist majorly in the positively charged form. The carbonyl groups of $\mathrm{UiO}-66-\mathrm{NO}_{2}$ are protonated, which undergo hydrogen bond interaction with the nitrogen atoms of $\mathrm{MB}$ molecules. The hydrogen bond interaction is stronger than the electrostatic repulsion. Therefore, the increase of $\mathrm{pH}$ from 2.0 to 3.0 reduces the amount of the protonation hydrogen atoms, which reduces the adsorption capacity of $\mathrm{MB}$ onto $\mathrm{UiO}-66-$ $\mathrm{NO}_{2}$. From $\mathrm{pH} 3.0$ to 5.0, the adsorption of $\mathrm{MB}$ onto UiO$66-\mathrm{NO}_{2}$ increases. In this $\mathrm{pH}$ range, the charge of $\mathrm{MB}$ changes from positive to neutral, which eliminates the electrostatic repulsion between $\mathrm{UiO}-66-\mathrm{NO}_{2}$ and $\mathrm{MB}$ molecules that improves the adsorption capacity. From $\mathrm{pH}$ 5.0 to 6.0 , the adsorption of $\mathrm{MB}$ onto $\mathrm{UiO}-66-\mathrm{NO}_{2}$ was reduced. In this range, the charge of $\mathrm{UiO}-66-\mathrm{NO}_{2}$ changes from positive to negative, which results in the electrostatic repulsion with the negatively charged $\mathrm{MB}$ molecules. Upon increasing $\mathrm{pH}$ from 6.0 to 8.0 , the adsorption of $\mathrm{MB}$ onto UiO-66- $\mathrm{NO}_{2}$ increases. During this, the surface charge of

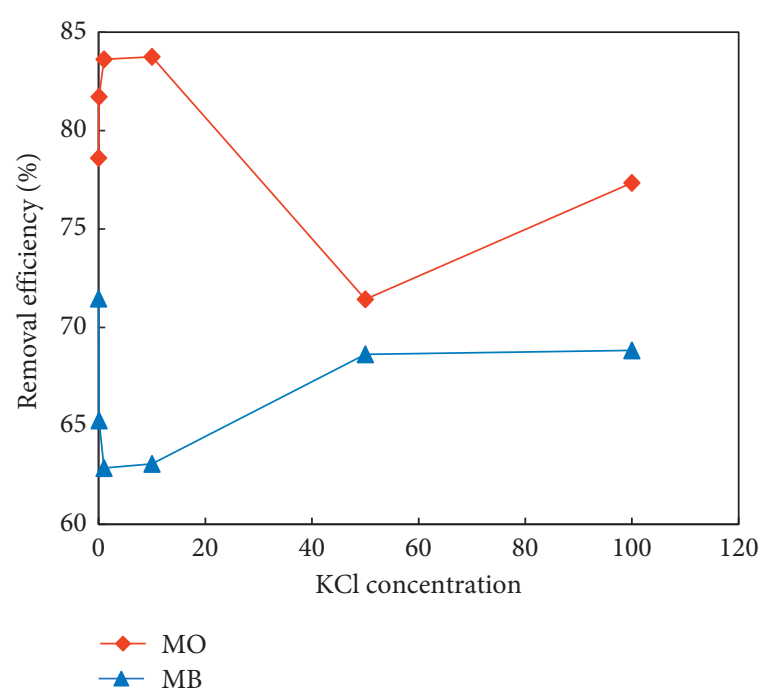

Figure 9: Influence of $\mathrm{KCl}$ on the adsorption of $\mathrm{MB}$ and $\mathrm{MO}$ by $\mathrm{UiO}-66-\mathrm{NO}_{2}$.

UiO-66- $\mathrm{NO}_{2}$ changes from positive to negative, indicating the key role of the electrostatic interaction between negatively charged $\mathrm{UiO}-66-\mathrm{NO}_{2}$ and the $\mathrm{MB}$ molecules with partially positive charges. However, the overall impact of the hydrogen bond interaction between $\mathrm{UiO}-66-\mathrm{NO}_{2}$ and $\mathrm{MB}$ molecules is still predominant, but less than in case of MO. Therefore, the impact of the electrostatic repulsion and attraction was seeable in some cases. It also indicates that the nonelectrostatic interaction in case of $\mathrm{MO}$ is remarkably higher than in case of $\mathrm{MB}$, which partially explains the higher $q_{\max }$ value of $\mathrm{MO}$ over $\mathrm{MB}$.

To more precisely evaluate the impact of the electrostatic interaction, the adsorption of $\mathrm{MB}$ and $\mathrm{MO}$ was measured under the addition of different amounts of $\mathrm{KCl}$. The presence of $\mathrm{KCl}$ in the solution increases the ionic strength. As can be seen, the addition of $\mathrm{KCl}$ has no great impact on the adsorption of both $\mathrm{MB}$ and $\mathrm{MO}$, thus confirming the minor impact of the electrostatic interaction of these dyes with $\mathrm{UiO}-66-\mathrm{NO}_{2}$. It is notable to mention that $\mathrm{MO}$ and $\mathrm{MB}$ were in the negative and positive form at the experiment condition known as the neutral condition because this $\mathrm{pH}$ was higher than $\mathrm{pK}_{\mathrm{a}}$ of both $\mathrm{MO}\left(\mathrm{pK}_{\mathrm{a}}=3.7\right)$ and $\mathrm{MB}\left(\mathrm{pK}_{\mathrm{a}}=3.8\right)$. Moreover, the isoelectric point of $\mathrm{UiO}-66-\mathrm{NO}_{2}$ was 4.6 ; thus, the surface of the material was negatively charged at a neutral condition. Therefore, as can be seen in Figure 9, at low $\mathrm{KCl}$ concentration, $\mathrm{K}^{+}$ion neutralized the negative charge of the material surface that facilitated the adsorption of $\mathrm{MO}$ on the surface but enhanced the repulsion between $\mathrm{MB}$ and the surface of $\mathrm{UiO}-66-\mathrm{NO}_{2}$. Consequently, the $\mathrm{MO}$ adsorption ability of the material enhanced, while the $\mathrm{MB}$ adsorption ability was in an opposite behavior.

At higher $\mathrm{KCl}$ concentration, the $\mathrm{MO}$ adsorption was remarkably decreased plausibly because of the interaction between the $\mathrm{K}^{+}$ion and the negatively charged $\mathrm{MO}$ adsorbate, which reduced the affinity of MO and the surface. In the case of $\mathrm{MB}$ adsorption, the increase of $\mathrm{KCl}$ concentration limited the dissociation of $\mathrm{MB}$ molecules, which in turn 
reduced its repulsive interaction with the surface. As a result, the $\mathrm{MO}$ adsorption ability was reduced, while that of $\mathrm{MB}$ was increased.

\section{Conclusion}

The adsorption of methylene blue and methyl orange by $\mathrm{UiO}-66-\mathrm{NO}_{2}$ nanoparticles was investigated. It was found that the adsorption of these dyes by $\mathrm{UiO}-66-\mathrm{NO}_{2}$ takes place in both intraparticle and interparticle spaces. The kinetics of the adsorption fits moderately with the pseudo-first-order, but perfectly fits with pseudo-second-order models, and has a very good fit with the Elovich and intraparticle models. There is a slight difference in the adsorption mechanism of $\mathrm{MB}$ and $\mathrm{MO}$ onto $\mathrm{UiO}-66-\mathrm{NO}_{2}$. However, for both dyes, the interaction between these solutes and the adsorbents is chemisorption, and the intraparticle diffusion is the ratedetermining step. The adsorption capacity of methyl orange was greater than that of methylene blue. The reason might be due to the negative mesomeric effect of the $-\mathrm{NO}_{2}$ groups involved in the structure of $\mathrm{UiO}-66-\mathrm{NO}_{2}$, which probably improves both $\pi-\pi$ stacking and hydrogen bonds with the dye molecules. The hydrogen bonds have probably the predominant impact on the attraction between $\mathrm{UiO}-66-\mathrm{NO}_{2}$ and the dye molecules.

\section{Data Availability}

The data used to support the findings of this study are included within the article.

\section{Conflicts of Interest}

The authors declare that they have no conflicts of interest.

\section{Acknowledgments}

This research was funded by Vietnam National University, Hanoi (VNU) (project no. QG.19.10). All authors would like to thank for the approval of this funding.

\section{Supplementary Materials}

Figure S1: TEM image of $\mathrm{UiO}-66-\mathrm{NO}_{2}$. Figure S2: pseudofirst-order kinetic model of $\mathrm{MB}$ adsorption onto $\mathrm{UiO}-66-$ $\mathrm{NO}_{2}$. Figure S3: pseudo-first-order kinetic model of $\mathrm{MO}$ adsorption onto $\mathrm{UiO}-66-\mathrm{NO}_{2}$. Figure S4: pseudo-secondorder kinetic model of $\mathrm{MB}$ adsorption onto $\mathrm{UiO}-66-\mathrm{NO}_{2}$. Figure S5: pseudo-second-order kinetic model of $\mathrm{MO}$ adsorption onto $\mathrm{UiO}-66-\mathrm{NO}_{2}$. Figure $\mathrm{S} 6$ : Elovich adsorption model of $\mathrm{MB}$ adsorption onto $\mathrm{UiO}-66-\mathrm{NO}_{2}$ nanoparticles. Figure S7: Elovich adsorption model of $\mathrm{MO}$ adsorption onto UiO-66- $\mathrm{NO}_{2}$ nanoparticles. Figure S8: intraparticle adsorption model of $\mathrm{MB}$ adsorption onto $\mathrm{UiO}-66-\mathrm{NO}_{2}$. Figure S9: intraparticle adsorption model of $\mathrm{MO}$ adsorption onto UiO-66- $\mathrm{NO}_{2}$. (Supplementary Materials)

\section{References}

[1] K. K. Samanta, P. Pandit, P. Samanta, and S. Basak, Water Consumption in Textile Processing and Sustainable Approaches for its Conservation, Elsevier, Amsterdam, Netherlands, 2019.

[2] P. Pattnaik, G. S. Dangayach, and A. K. Bhardwaj, "A review on the sustainability of textile industries wastewater with and without treatment methodologies," Reviews on Environmental Health, vol. 33, no. 2, pp. 163-203, 2018.

[3] M. Sakamoto, T. Ahmed, S. Begum, and H. Huq, "Water pollution and the textile industry in Bangladesh: flawed corporate practices or restrictive opportunities?" Sustain, vol. 11, 2019.

[4] E. A. Dil, M. Ghaedi, A. M. Ghaedi et al., "Modeling of quaternary dyes adsorption onto $\mathrm{ZnO}-\mathrm{NR}-\mathrm{AC}$ artificial neural network: analysis by derivative spectrophotometry," Journal of Industrial and Engineering Chemistry, vol. 34, pp. 186-197, 2016.

[5] F. Fish, W. C. Commission, and P. Charlotte, "Short-term effects of a low dissolved oxygen event on estuarine fish assemblages following the passage of hurricane Charley," Estuaries and Coasts, vol. 29, pp. 997-1003, 2006.

[6] D. L. Breitburg, A. Adamack, K. A. Rose et al., "The pattern and influence of low dissolved oxygen in the Patuxent River, a seasonally hypoxic estuary," Estuaries, vol. 26, no. 2, pp. 280-297, 2003.

[7] R. O. Alves de Lima, A. P. Bazo, D. M. F. Salvadori, C. M. Rech, D. de Palma Oliveira, and G. de Aragão Umbuzeiro, "Mutagenic and carcinogenic potential of a textile azo dye processing plant effluent that impacts a drinking water source," Mutation Research/Genetic Toxicology and Environmental Mutagenesis, vol. 626, no. 1-2, pp. 53-60, 2007.

[8] V. K. Gupta, R. Jain, A. Nayak, S. Agarwal, and M. Shrivastava, "Removal of the hazardous dye-Tartrazine by photodegradation on titanium dioxide surface," Materials Science and Engineering: C, vol. 31, no. 5, pp. 1062-1067, 2011.

[9] N. Mohammadi, H. Khani, V. K. Gupta, E. Amereh, and S. Agarwal, "Adsorption process of methyl orange dye onto mesoporous carbon material-kinetic and thermodynamic studies," Journal of Colloid and Interface Science, vol. 362, no. 2, pp. 457-462, 2011.

[10] Division of Microbiology, Food and Drug Administration, Jefferson, AR 72079-9502, pp. 568-586, National Center for Toxicological Research, U.S, Washington, DC, USA, 2012.

[11] Y. N. Sundukov, "First record of the ground beetle trechoblemus postilenatus (Coleoptera, Carabidae) in primorskii krai, far east," Entomology, vol. 165, p. 16, 2006.

[12] T. Ito, Y. Adachi, Y. Yamanashi, and Y. Shimada, "Long-term natural remediation process in textile dye-polluted river sediment driven by bacterial community changes," Water Research, vol. 100, pp. 458-465, 2016.

[13] F. Copaciu, O. Opriş, V. Coman, D. Ristoiu, Ü. Niinemets, and L. Copolovici, "Diffuse water pollution by anthraquinone and azo dyes in environment importantly alters foliage volatiles, carotenoids and physiology in wheat (Triticum aestivum)," Water, Air, \& Soil Pollution, vol. 224, 2013.

[14] B. J. Brüschweiler and C. Merlot, "Azo dyes in clothing textiles can be cleaved into a series of mutagenic aromatic amines which are not regulated yet," Regulatory Toxicology and Pharmacology, vol. 88, pp. 214-226, 2017.

[15] A. R. Tehrani-Bagha, N. M. Mahmoodi, and F. M. Menger, "Degradation of a persistent organic dye from colored textile 
wastewater by ozonation," Desalination, vol. 260, no. 1-3, pp. 34-38, 2010.

[16] X.-R. Xu, H.-B. Li, W.-H. Wang, and J.-D. Gu, "Degradation of dyes in aqueous solutions by the Fenton process," Chemosphere, vol. 57, no. 7, pp. 595-600, 2004.

[17] H. Zangeneh, A. A. L. Zinatizadeh, M. Habibi, M. Akia, and M. Hasnain Isa, "Photocatalytic oxidation of organic dyes and pollutants in wastewater using different modified titanium dioxides: a comparative review," Journal of Industrial and Engineering Chemistry, vol. 26, pp. 1-36, 2015.

[18] M. T. Yagub, T. K. Sen, S. Afroze, and H. M. Ang, "Dye and its removal from aqueous solution by adsorption: a review," Advances in Colloid and Interface Science, vol. 209, pp. 172184, 2014.

[19] C. Thamaraiselvan and M. Noel, "Membrane processes for dye wastewater treatment: recent progress in fouling control," Critical Reviews in Environmental Science and Technology, vol. 45, no. 10, pp. 1007-1040, 2015.

[20] V. K. Suhas and V. K. Gupta, "Cellulose: a review as natural, modified and activated carbon adsorbent," Bioresource Technology, vol. 216, pp. 1066-1076, 2016.

[21] V. K. Gupta and T. A. Saleh, "Sorption of pollutants by porous carbon, carbon nanotubes and fullerene- an overview," Environmental Science and Pollution Research, vol. 20, pp. 2828-2843, 2013.

[22] H. Y. Chi, S. H. Hung, M. Y. Kan et al., "Metal-organic frameworks for dye sorption: structure-property relationships and scalable deposition of the membrane adsorber," CrystEngComm Journal, vol. 20, pp. 5465-5474, 2018.

[23] A. A. Adeyemo, I. O. Adeoye, and O. S. Bello, "Metal organic frameworks as adsorbents for dye adsorption: overview, prospects and future challenges," Toxicological \& Environmental Chemistry, vol. 94, pp. 1846-1863, 2012.

[24] D. Jiang, M. Chen, H. Wang et al., "The application of different typological and structural MOFs-based materials for the dyes adsorption," Coordination Chemistry Reviews, vol. 380, pp. 471-483, 2019.

[25] M. S. A. Eren, H. Arslanoglu, and H. Çiftçi, "Production of microporous $\mathrm{Cu}$-doped BTC (Cu-BTC) metal-organic framework composite materials, superior adsorbents for the removal of methylene blue (Basic Blue 9)," Journal of Environmental Chemical Engineering, vol. 8, 2020.

[26] Y. Y. Cui, J. Zhang, L. L. Ren, A. L. Cheng, and E. Q. Gao, “A functional anionic metal-organic framework for selective adsorption and separation of organic dyes," Polyhedron, vol. 161, pp. 71-77, 2019.

[27] Q. Zha, X. Sang, D. Liu, D. Wang, G. Shi, and C. Ni, "Modification of hydrophilic amine-functionalized metalorganic frameworks to hydrophobic for dye adsorption," Journal of Solid State Chemistry, vol. 275, pp. 23-29, 2019.

[28] Q. Chen, Q. He, M. Lv et al., "Selective adsorption of cationic dyes by UiO-66-NH2," Applied Surface Science, vol. 327, pp. 77-85, 2015.

[29] N. C. Burtch, H. Jasuja, and K. S. Walton, "Water stability and adsorption in metal-organic frameworks," Chemical Reviews, vol. 114, pp. 10575-10612, 2014.

[30] S. Zeng, F. Lyu, L. Sun et al., "UiO-66-NO 2 as an oxygen "pump" for enhancing oxygen reduction reaction performance," Chemistry of Materials, vol. 31, pp. 1646-1654, 2019.

[31] D. X. Trinh, T. Phuong, N. Tran, and T. Taniike, "Fabrication of new composite membrane filled with UiO-66 nanoparticles and its application to nanofiltration," Separation and Purification Technology, vol. 177, pp. 249-256, 2017.
[32] Z. Jin and H. Yang, "Exploration of Zr-Metal-Organic framework as efficient photocatalyst for hydrogen production," Nanoscale Research Letters, vol. 12, 2017.

[33] Q. Yang, A. D. Wiersum, P. L. Llewellyn, V. Guillerm, C. Serre, and G. Maurin, "Functionalizing porous zirconium terephthalate $\mathrm{UiO}-66(\mathrm{Zr})$ for natural gas upgrading: a computational exploration," Chemical Communications, vol. 47, pp. 9603-9605, 2011.

[34] S. B. Kalidindi, S. Nayak, M. E. Briggs et al., "Chemical and structural stability of zirconium-based metal-organic frameworks with large three-dimensional pores by linker engineering," Angewandte Chemie, vol. 54, pp. 221-226, 2015.

[35] F. Ragon, B. Campo, Q. Yang et al., "Acid-functionalized $\mathrm{UiO}-66(\mathrm{Zr}) \mathrm{MOF}$ and their evolution after intra-framework cross-linking: structural features and sorption properties," Journal of Materials Chemistry A, vol. 3, pp. 3294-3309, 2015.

[36] Z. H. Rada, H. R. Abid, H. Sun et al., "Effects of -NO2 and -NH2 functional groups in mixed-linker Zr-based MOFs on gas adsorption of CO2 and CH4," Progress in Natural Science: Materials International, vol. 28, pp. 160-167, 2018.

[37] X. Song, P. Yang, D. Wu et al., "Facile synthesis of metalorganic framework $\mathrm{UiO}-66$ for adsorptive removal of methylene blue from water," Chemical Physics, vol. 531, Article ID 110655, 2020.

[38] Z. Fang, B. Bueken, D. E. De Vos, and R. A. Fischer, "Defectengineered metal-organic frameworks," Angewandte Chemie, vol. 54, pp. 7234-7254, 2015.

[39] M. J. Cliffe, W. Wan, X. Zou et al., "Correlated defect nanoregions in a metal-organic framework," Nature Communications, vol. 5, pp. 1-8, 2014.

[40] S. Kim, J. Lee, Y. Son, and M. Yoon, "Study of the dye adsorption kinetics of metal-organic frameworks in aqueous media," Bulletin of the Korean Chemical Society, vol. 41, pp. 843-850, 2020.

[41] C. M. Frey, "Diesel exhaust particulates," Nature Publishing Group, vol. 216, pp. 615-616, 1967.

[42] F. C. Wu, R. L. Tseng, and R. S. Juang, "Characteristics of Elovich equation used for the analysis of adsorption kinetics in dye-chitosan systems," Chemical Engineering Journal, vol. 150, pp. 366-373, 2009.

[43] J. Wang and X. Guo, "Adsorption isotherm models: Classification, physical meaning, application and solving method," Chemosphere, vol. 258, Article ID 127279, 2020.

[44] F. Nekouei, S. Nekouei, I. Tyagi, and V. K. Gupta, "Kinetic, thermodynamic and isotherm studies for acid blue 129 removal from liquids using copper oxide nanoparticle-modified activated carbon as a novel adsorbent," Journal of Molecular Liquids, vol. 201, pp. 124-133, 2015.

[45] X. Guo and J. Wang, "Comparison of linearization methods for modeling the Langmuir adsorption isotherm," Journal of Molecular Liquids, vol. 296, Article ID 111850, 2019.

[46] C. S. Wu, Z. H. Xiong, C. Li, and J. M. Zhang, "Zeolitic imidazolate metal organic framework ZIF-8 with ultra-high adsorption capacity bound tetracycline in aqueous solution," RSC Advances, vol. 5, pp. 82127-82137, 2015.

[47] M. Dakiky, M. Khamis, A. Manasra, and K. Takrouri, "Effect of surfactants on the thermodynamic properties of Methys Orange dye in buffered solutions, Color," Technology Engineering, vol. 118, pp. 191-197, 2002.

[48] H. R. Sousa, L. S. Silva, P. A. A. Sousa et al., "Evaluation of methylene blue removal by plasma activated palygorskites," Journal of Materials Research and Technology, vol. 8, pp. 5432-5442, 2019. 